Article

\title{
Evaluation of Accuracy and Precision of the Sound-Recorder-Based Point-Counts Applied in Forests and Open Areas in Two Locations Situated in a Temperate and Tropical Regions
}

\author{
Michał Budka*(D), Kinga Kułaga (D) and Tomasz Stanislaw Osiejuk (D) \\ Department of Behavioural Ecology, Faculty of Biology, Adam Mickiewicz University in Poznań, \\ Uniwersytetu Poznańskiego 6, 61614 Poznań, Poland; kinga.kulaga96@gmail.com (K.K.); \\ osiejuk@amu.edu.pl (T.S.O.) \\ * Correspondence: m.budka@amu.edu.pl
}

Citation: Budka, M.; Kułaga, K.; Osiejuk, T.S. Evaluation of Accuracy and Precision of the Sound-RecorderBased Point-Counts Applied in Forests and Open Areas in Two Locations Situated in a Temperate and Tropical Regions. Birds 2021, 2, 351-361. https://doi.org/10.3390/birds2040026

Academic Editor: Jukka Jokimäki

Received: 7 September 2021

Accepted: 19 October 2021

Published: 21 October 2021

Publisher's Note: MDPI stays neutral with regard to jurisdictional claims in published maps and institutional affiliations.

Copyright: (c) 2021 by the authors. Licensee MDPI, Basel, Switzerland. This article is an open access article distributed under the terms and conditions of the Creative Commons Attribution (CC BY) license (https:/ / creativecommons.org/licenses/by/ $4.0 /)$.
Simple Summary: Counting from points is one of the most popular techniques for surveying birds, and it is applied in various environments, from polar to tropical regions. Across such a wide range of environmental conditions, the effectiveness of this method may vary considerably. In this study, we applied autonomous sound recorders to examine whether effectiveness of the method in bird biodiversity estimation differ depending on the geographical region (tropical vs. temperate), habitat type (forest vs. open area) and the time of day at which the survey began. We found that pointcounts provided statistically indistinguishable estimates of bird biodiversity in different geographical regions and habitats. However, during a single 5-min survey, only $41-54 \%$ of species present at the recording site were detected. Independent of the region or habitat type, we recorded significantly more species at sunrise than during later surveys. Our study showed that point-counts provided similar estimates of bird biodiversity in various habitat types and geographical regions. At the same time, the low proportion of detected species during a single survey limits the usefulness of the method in studying bird-environment relationships (e.g., habitat preferences), while decreasing number of detected species across the day may result in the misinterpretation of the status of bird populations when early and late surveys are compared without controlling this factor.

Abstract: The point-count method is one of the most popular techniques for surveying birds. However, the accuracy and precision of this method may vary across various environments and geographical regions. We conducted sound-recorder-based point-counts to examine the accuracy and precision of the method for bird biodiversity estimation as a function of geographical region, habitat type and the time of day at which the survey began. In temperate (Poland) and tropical (Cameroon) regions, we recorded soundscapes on two successive mornings at 36 recording sites (18 in each location). At each site, we analyzed three 5-min surveys per day. We found no differences in the accuracy and precision of the method between regions and habitats. The accuracy was significantly greater at sunrise than during later surveys. The similarity of the bird assemblages detected by different surveys did not differ between regions or habitats. However, the bird communities described at the same time of day were significantly more similar to each other than those detected by surveys conducted at different times. The point-count method provided statistically indistinguishable estimates of bird biodiversity in different geographical regions and habitats. However, our results highlight two weaknesses of the method: low accuracy (41-54\%), which limits the usefulness of a single survey in understanding bird-environment relationships, and changes in accuracy throughout the day, which may result in the misinterpretation of the status of bird populations.

Keywords: bird survey; bird monitoring; autonomous sound recording; tropics; temperate region; effectiveness of point-count method; bird biodiversity; acoustic monitoring 


\section{Introduction}

The point-count method is one of the most popular techniques for surveying birds, used for estimating abundance, density, species richness, distribution, and relations between birds and environment [1-3]. However, this method does not provide real values but estimates of measured parameters $[4,5]$. Therefore, knowing the accuracy and precision of any applied variants of the method for surveying birds is important. Accuracy describes how close the estimate is to the true value, whereas precision is a measure of how close replicated estimates are to each other and is unrelated to the true value of species abundance or distribution [5].

For point-counts, accuracy and precision in the context of species richness estimation are influenced by the detectability of particular species in a bird community [5]. Detectability of a species is determined by the detection probabilities of each individual present in a given area $(\mathrm{D}=1-(1-\mathrm{p}) \mathrm{N}$, where $\mathrm{D}=$ detectability of a species, $\mathrm{p}=$ probability of detecting an individual, and $\mathrm{N}=$ number of individuals), which varies among species and depends on a number of variables, including specific behavior (e.g., secretive vs. vociferous), territory size, habitat (open vs. closed), and inhabited vegetation layer (understory vs. emergent layer) [6,7]. Thus, by applying a given set of methodological assumptions (e.g., constant detection distance, time and duration of survey, observer skills, and weather conditions), different species are detected with different probabilities [8].

Point-counts have been used to survey birds in a variety of habitats, ranging from dense forests to completely open areas, and from polar to tropical regions $[9,10]$. These environments have species that differ in detection probability during a single survey, and the combination of detection probabilities of the species reflects the effectiveness of the surveying method in the context of the whole bird community within the studied environment. Therefore, we may expect variation in the precision and accuracy of the pointcounts in different habitats and geographical regions, even when the same methodological assumptions are applied. Moreover, typical monitoring schemes assume that field surveys are conducted in a specific period of the season (e.g., one month) and time of day (e.g., from one hour before sunrise to four hours after sunrise). Such assumptions lead to inconsistencies in the accuracy and precision of the method, since the probability of species detection varies daily and seasonally.

Differences in detectability have been characterized for many bird species, especially in temperate regions $[7,8,11,12]$. However, most studies have focused on a single geographical region, a single type of environment, or a selected species from the whole bird assemblage. Therefore, it is important to know how effective point-counts are in estimating bird species' richness, assuming that the same methodological assumptions are applied under different environmental conditions and geographical regions.

We focused on the accuracy and precision of the acoustic-recorder-based point-count method for estimating breeding bird species' richness in forests and open habitats of tropical and temperate regions. The detectability of a species strongly depends on survey methods, e.g., survey duration, time of day, stage of the breeding season, weather conditions, the size of the area sampled around points, and the skill and experience of observers [4,11,13-15]. For this reason, we standardized the survey method. In both locations, we surveyed birds in the peak of the breeding season of most species and maintained constant survey duration, time of day, and detection range for the species within recording site. However, detection distance varied between species due to differences in species' frequency ranges and amplitude influencing the effective detection distances, and it varied between habitats, because effective detection distance is shorter in open habitats than in forests. We also minimized the effect of the observer's skills and applied a standardized approach throughout the study. We replaced human-observers surveying birds in the field within unlimited distance with autonomous sound recorders. Autonomous sound recorders enable users to record soundscapes and are a promising alternative to human-based point-counts for estimation of abundance, density, occupancy, or bird species' richness [16,17]. Many investigators have compared the effectiveness of bird species' richness estimated by autonomous sound 
recorders and human-based point-counts. The results showed higher effectiveness of human-observers [18], recorders [19], or no differences between methods [20]. This inconsistency may arise from three factors: varying skills of the observers who surveyed birds in the field (low-skilled observers should support recorders), varying detection ranges applied by observers (unlimited radius should support observers), and different types of habitats in which comparisons were made. However, a recent meta-analysis showed that bird species' richness estimated by human-observers and autonomous sound recorders surveying birds at the same time is statistically indistinguishable when detection distance is controlled [21]. One reason is that human-observers, especially in forest habitats, detect most birds by using auditory cues [22]. Thus, in our study, autonomous sound recorders should provide a similar estimate of bird species' richness as human-observers. Applying autonomous sound recorders allowed us to survey birds at the same time at multiple sites. Using the same model of sound recorder, we kept the detection range constant at the recording sites (generally shorter than that of a human-observer without distance limitation; [23]) and, most importantly, minimized the effect of observer's skills and experience. In the field, observers may not detect or may incorrectly identify a species, and these sources of error can bias the results of a study [24,25]. We analyzed soundscape recordings in the lab, so we were able to listen to them many times and compare vocalizations with samples from sound libraries when we had difficulty identifying species.

Our objective was to examine the precision and accuracy of the recorder-based pointcount method in estimating breeding bird species' richness in two different geographical regions (temperate vs. tropical), two different habitat conditions (forest vs. open), and at different times of day (sunrise and one and two hours after sunrise). Our goal was not to optimize the method or estimating bird biodiversity for a given location but to assess how well a particular variant of the method works in different environmental conditions, and how the time of the survey influences estimated bird-species richness from the perspective of an individual recording site and a single survey.

\section{Materials and Methods}

\subsection{Study Area}

We conducted our study in two locations (Tables S1 and S2), representing a temperate region (Upper Nurzec River Valley, eastern Poland; coordinates: N52.597521 ${ }^{\circ}, \mathrm{E} 23.230633^{\circ}$ ) and a tropical region (Bamenda Highlands, Northwest Cameroon; coordinates: N6.090594 , E10.298807º.

The Upper Nurzec River Valley is a 4000 ha Important Bird Area of international importance in Poland (PL056), protected as part of the Natura 2000 conservation network [25]. This area has temperate climate, with warm summers (an average temperature in June is $18^{\circ} \mathrm{C}$ ) and cold winters (an average temperature in January is $-6^{\circ} \mathrm{C}$ ). Annual precipitation in the region oscillates from 600 to $700 \mathrm{~mm}$, and annual mean temperatures are from $8.7^{\circ} \mathrm{C}$ to $9.3^{\circ} \mathrm{C}$ [26]. The Upper Nurzec River Valley is a compact complex of drained alluvial agricultural meadows and wastelands, with low coverage by forests and arable fields, located at elevations from 144 to $162 \mathrm{~m}$ a.s.l. The number of breeding bird species was estimated to be 111 [27], the breeding season for most species extends from beginning of April to the end of June [28], and most bird species leave the area for the winter.

The Bamenda Highlands are part of the Cameroon Mountains Endemic Bird Area [29]. This area has a short dry season (from November to February) and a long wet season (March-October; [30]). Annual precipitation ranges from 2300 to $3000 \mathrm{~mm}$, and annual mean temperatures range from $18.7^{\circ} \mathrm{C}$ to $21.0^{\circ} \mathrm{C}$ [31]. Our study area covered a nonprotected area of $\sim 400$-ha located near the village of Big Babanki (Northwest Region, Cameroon; 1824-2340 m a.s.l). The habitat consisted of a mosaic of fragments of upper montane rainforests, woodlands, forest clearings, stream corridors, shrub vegetation, pastures, and abandoned lands under succession by shrubs and ferns. In our study location, most species of birds breed during the dry season, from October to March [32,33]. 
The local breeding bird community included an estimated 109 species [33]; most of them are resident.

\subsection{Soundscape Recording and Analysis}

We used Song Meter SM2 autonomous sound recorders (two omnidirectional microphones SMX-II, signal-to-noise ratio $>62 \mathrm{~dB}$; Wildlife Acoustics) to collect soundscape recordings in the Bamenda Highlands, and Song Meter SM3 recorders (two omnidirectional microphones SMM-A1, signal-to-noise ratio > $68 \mathrm{~dB}$; Wildlife Acoustics) in the Upper Nurzec River Valley. The detection range of recorders is generally shorter than the human detection range; is species-specific (species producing lower-frequency and louder sounds are detected from a further distance); and depends on vegetation type (detection range is longer in open habitats than in forests), humidity (positive effect on detection range), and wind conditions (negative effect on detection range) [23]. The comparison of the two models of recorders we used suggests that SM2 has a slightly shorter effective detection range than SM3, but the difference depends on frequency of sound and habitat type [23]. However, for the purpose of the study, we did not apply a correction for effective detection distance related with species, recorder and vegetation type, humidity, and wind. At each location, we recorded soundscapes at 18 randomly chosen recording sites, including nine located in forests and nine in open areas. We defined forests as an area of land dominated by trees, whereas open areas included meadows, pastures, and abandoned lands with herbaceous vegetation, ferns, or shrubs. Recorders were attached to shrubs or trees between 2 and $5 \mathrm{~m}$ aboveground. We collected soundscape data on two successive mornings at each site when weather conditions were suitable (no rain or strong wind). We used the same recording settings at both locations (stereo recordings, 16-bit PCM WAV recording format, and $48.0 \mathrm{kHz}$ sample rate; no low- or high-pass filter applied).

In the Bamenda Highlands, we recorded soundscapes from 16 November to 12 December 2010 (14 recording sites) and 2011 (four recording sites), corresponding to the beginning of the breeding season in this region [33]. The average linear distance between neighboring recording sites was $287 \mathrm{~m}$ (range $=89-630 \mathrm{~m}$; the closest recording sites were located on opposite sides of a hillcrest, so soundscapes did not overlap). In the Upper Nurzec Valley, we recorded soundscapes from 3 to 7 May 2018, corresponding to the beginning of the breeding season for most bird species [28]. The average linear distance between neighboring recording sites was $568 \mathrm{~m}$ (range $=334-1212 \mathrm{~m}$ ).

At each recording site, we selected and analyzed three sound samples, each 5-min long, per day, that began at sunrise, one hour after sunrise, and two hours after sunrise (early, intermediate, and late survey, respectively). A 5-min survey duration is often used by human-observers to survey birds in the field, and this duration is usually sufficient to determine the structure of a bird community [34]. In total, at each recording site, we analyzed $30 \mathrm{~min}$ of soundscape recordings (3 per day $\times 5 \min \times 2$ days), using Avisoft SAS Lab Pro 5.2.13 software. We generated spectrograms with the following settings: FFT length $=1024$, frame size $=75 \%$, Window $=$ Hamming, and overlap $=50 \%$. We then manually scanned spectrograms and listened to recordings to detect and identify all bird vocalizations. Recordings were analyzed by two experienced observers (KK-recordings from Upper Nurzec River Valley; MB—recordings from Bamenda Highlands). When we had difficulties with species identification, we compared the unknown sound with examples of bird vocalizations from www.xeno-canto.org, accessed on 21 October 2021 (Xeno-Canto Foundation). For each 5-min recording, we prepared a list of species detected.

\subsection{Statistical Analyses}

First, we determined if the number of bird species detected at a recording site depended on the region where the survey was conducted (tropical vs. temperate), the habitat type (forest vs. open area), the day of survey (first or second), or the time of day (early, intermediate, or late). For this, we used generalized estimating equations (GEEs). GEEs extend the generalized linear model to allow for analysis of repeated measurements or other 
correlated observations [35]. In the model, we used the number of detected bird species as the dependent variable, and region, habitat, day, and time of survey as predictors. In the GEEs, we specified each recording site as a subject variable, and survey as a within-subject variable. Data were fitted by a negative binomial distribution with a log-link function.

In the second step, we estimated the accuracy of a single survey by calculating the ratio of the number of bird species detected during a single survey to the total number of bird species detected during all six surveys at the recording site. Our assumption was that, over the course of six surveys, we would detect almost all species breeding around the recording site, but not all. We then applied GEEs to determine if the accuracy of a single 5-min survey differed between regions, habitats, days, or times of day. Again, we specified the recording site as a subject variable, and survey as a within-subject variable in the GEEs. Data were fitted by a gamma distribution with a log-link function.

To compare the precision of applied recorder-based point-count method (i.e., the repeatability of results delivered by different point-counts conducted in the same recording site) between habitats and regions, we calculated the standard error of the mean number of species recorded in each recording site over the six surveys [5]. We then created a generalized linear model (GLM) with this value as the dependent variable, and region and habitat type as predictors. Data were fitted by a gamma distribution and log-link function.

In the last step, we compared the similarity of the bird assemblages that were detected in the different surveys conducted at the same recording site. For this, we applied a measure commonly used to compare species composition between two communities: Sørensen similarity index [36]. In our case, Sørensen similarity index $(\mathrm{QS}=2 \mathrm{C} /(\mathrm{A}+\mathrm{B}))$ counted the number of bird species recorded during each of two surveys at a recording site (Survey $\mathrm{A}$ and $B$ ), and the number of bird species detected by both (C). QS values can range from 0 (no bird species were detected by both surveys) to 1 (all bird species were observed during both surveys). We compared all possible combinations of surveys at the recording site (six surveys per recording site; ten combinations). We then applied GEEs to examine whether QS varied between regions, habitat types, days of survey, and times of survey. We specified the recording site as a subject variable, and comparison ID as a within-subject variable. Data were fitted by a normal distribution with identity link function. All statistical analyses were performed in IBM SPSS Statistics 26. We assumed a significance level of $\alpha=0.05$, and the tests were two-tailed.

\section{Results}

\subsection{Species Richness}

We recorded 51 bird species in the tropical region and 54 in the temperate region. On average, we observed $21.3 \pm 3.8$ species per recording site at the tropical region and $14.9 \pm 2.1$ at the temperate region (Mann-Whitney test: $Z=-4.196, p<0.001$ ). During a single survey, we recorded an average of $10.0 \pm 3.1$ species at tropical sites and $7.0 \pm 2.2$ at temperate regions (Mann-Whitney test: $\mathrm{Z}=-7.709, p<0.001$, Supplementary Materials Tables S1 and S2).

The GEE-based analysis revealed that the number of birds detected during 5-min surveys differed significantly by region (Wald $\chi^{2}=26.5, p<0.001$ ) and time of survey (Wald $\chi^{2}=28.1, p<0.001$ ), but not by habitat (Wald $\chi^{2}=0.03, p=0.87$ ) or day of survey (Wald $\chi^{2}=0.002, p=0.96$ ). We recorded significantly more species per survey in the tropical region than the temperate region, and during surveys conducted at sunrise than one or two hours after sunrise (Table 1 and Figure 1). 
Table 1. Results of generalized estimating equations examining the effect of region, habitat type, day, and time of survey on the number of bird species recorded during a single five-minute survey. As reference categories, we used tropical region, forest, first day, and early survey.

\begin{tabular}{|c|c|c|c|c|c|}
\hline Predictor & B & SE & Wald $\chi^{2}$ & $\mathrm{df}$ & $p$-Value \\
\hline Intercept & 2.442 & 0.0635 & 1480.179 & 1 & $<0.001$ \\
\hline Region (temperate) & -0.362 & 0.0703 & 26.536 & 1 & $<0.001$ \\
\hline Habitat (open habitats) & -0.012 & 0.0705 & 0.028 & 1 & 0.867 \\
\hline Day (second) & 0.002 & 0.0323 & 0.002 & 1 & 0.961 \\
\hline Survey (late) & -0.247 & 0.0528 & 21.890 & 1 & $<0.001$ \\
\hline Survey (intermediate) & -0.154 & 0.0335 & 21.050 & 1 & $<0.001$ \\
\hline
\end{tabular}

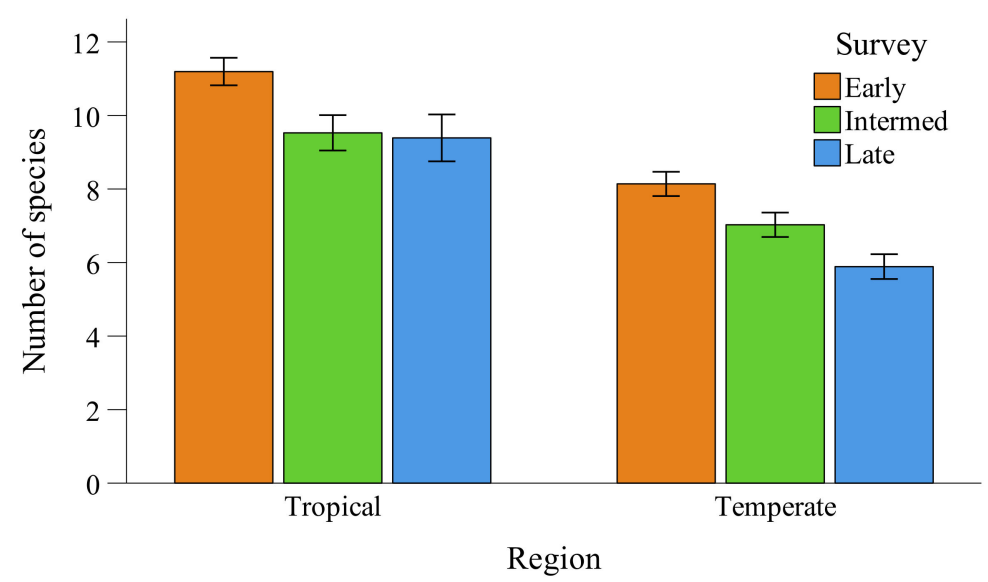

Figure 1. Average number of bird species $(+/-\mathrm{SD})$ recorded during a five-minute survey in tropical and temperate regions. Surveys started at sunrise (early), $1 \mathrm{~h}$ after sunrise (intermediate), and $2 \mathrm{~h}$ after sunrise (late). The significant differences $(p<0.001)$ in the number of detected bird species were observed between the regions, as well as between early vs. intermediate and late survey independently on the region.

\subsection{Accuracy and Precision of 5-min Surveys}

We found that the accuracy of a given survey depended on the time of the survey (Wald $\chi^{2}=28.9, p<0.001$ ), but not on region (Wald $\chi^{2}=0.003, p=0.96$ ), habitat (Wald $\chi^{2}=0.4$, $p=0.84$ ), or day (Wald $\chi^{2}=0.1, p=0.83$ ). Accuracy was significantly higher at sunrise ( $54 \%$ of bird biodiversity detected) than one or two hours after sunrise $(46 \%$ and $41 \%$ of bird biodiversity detected, respectively; Table 2 and Figure 2). We found no differences in the precision of surveys either between regions (Wald $\chi^{2}=1.2, p=0.28$ ) or habitats (Wald $\chi^{2}=0.01, p=0.92$ ). The average precision (measured as a standard error of the six surveys conducted at recording site) was 0.84 in the tropical region and 0.72 in the temperate region.

Table 2. Results of generalized estimating equations examining the effect of region, habitat type, day, and time of survey on the accuracy of a single five-minute survey. As reference categories, we used tropical region, forest, first day, and early survey.

\begin{tabular}{|c|c|c|c|c|c|}
\hline Predictor & B & SE & Wald $\chi^{2}$ & $\mathrm{df}$ & $p$-Value \\
\hline Intercept & -0.628 & 0.0439 & 205.055 & 1 & $<0.001$ \\
\hline Region (temperate) & -0.003 & 0.0501 & 0.003 & 1 & 0.955 \\
\hline Habitat (open habitats) & 0.032 & 0.0505 & 0.396 & 1 & 0.529 \\
\hline Day (second) & -0.008 & 0.0355 & 0.045 & 1 & 0.832 \\
\hline Survey (late) & -0.264 & 0.552 & 22.933 & 1 & $<0.001$ \\
\hline Survey (intermediate) & -0.160 & 0.0346 & 21.253 & 1 & $<0.001$ \\
\hline
\end{tabular}




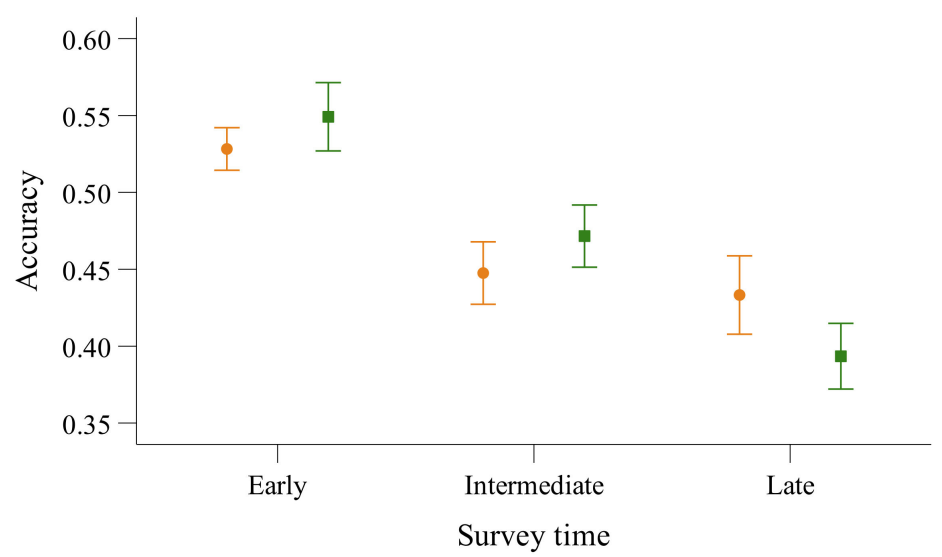

Figure 2. Accuracy of a single five-minute survey in tropical (orange) and temperate (green) region during early, intermediate, and late survey. Mean values and SE of means are given.

\subsection{Species Composition}

The average value of Sørensen similarity index for any two surveys at a recording site was 0.55 at tropical sites (range $=0-1$ ) and 0.56 at temperate sites (range $=0.15-0.89$ ) (Figure 3 ). No differences were found between tropical and temperate regions (Wald $\chi^{2}=0.02, p=0.89$ ) or between forests and open habitats (Wald $\chi^{2}=0.3, p=0.59$ ). However, we found that similarity values depended significantly on whether the two surveys were conducted on the same day (Wald $\chi^{2}=6.4, p=0.012$ ) or the same time of day (Wald $\chi^{2}=23.0, p<0.001$ ). Similarity was significantly lower for surveys conducted on the same day than on different days, and it was significantly higher for surveys conducted at the same time of day than at different times of the day (Table 3).

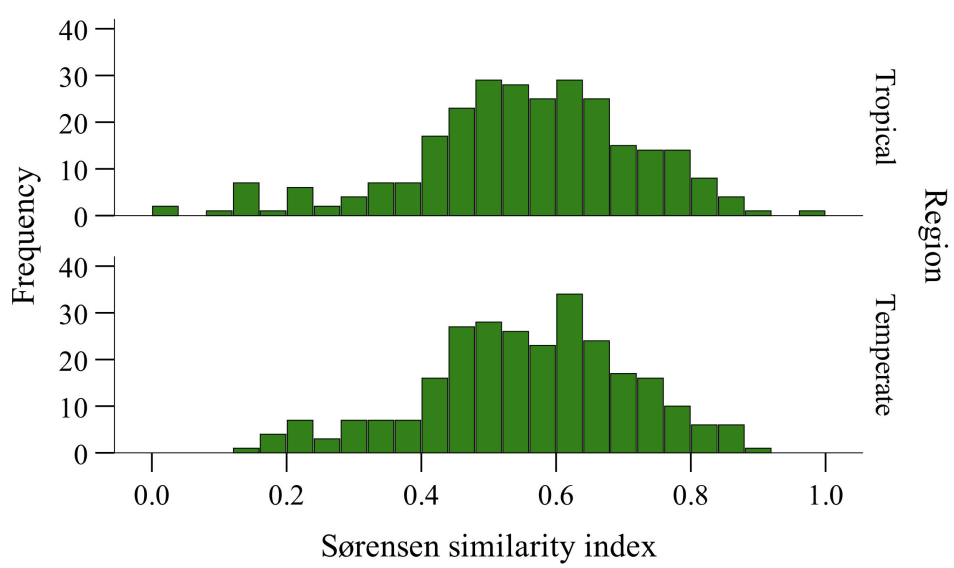

Figure 3. Distribution of Sørensen similarity index comparing bird species composition during two random surveys at recording site in tropical and temperate regions. Histogram based on comparisons of 540 pairs of surveys.

Table 3. Results of generalized estimating equations examining the effect of region, habitat type, day (surveys conducted on the same or different days), and time of survey (surveys conducted at the same time on different days or at different times) on values of Sørensen similarity index.

\begin{tabular}{cccccc}
\hline Predictor & B & SE & Wald $\chi^{2}$ & df & $p$-Value \\
\hline Intercept & 0.546 & 0.0266 & 420.792 & 1 & $<0.001$ \\
Region (temperate) & 0.004 & 0.0294 & 0.020 & 1 & 0.888 \\
Habitat (open habitats) & 0.016 & 0.0294 & 0.292 & 1 & 0.589 \\
Day (different) & -0.027 & 0.0106 & 6.361 & 1 & 0.012 \\
Time of survey (the same) & 0.069 & 0.0144 & 22.953 & 1 & $<0.001$ \\
\hline
\end{tabular}




\section{Discussion}

We detected no differences in the accuracy or precision of the recorder-based pointcount method, either between tropical and temperate regions or between forests and open habitats. Similarly, there was no effect of region or habitat on the species assemblage detected by multiple surveys at a given recording site (Sørensen similarity index). Thus, in the environments analyzed here, 5-min surveys provided estimates of bird-species richness that were statistically indistinguishable between regions and habitats. Our results are based on a specific approach where a human-observer surveying birds within unlimited radius was replaced by an autonomous sound recorder. Therefore, by using our method, we were unable to detect silent species that can be recorded visually by observers [18], but this bias concerned analyzed regions. The difference may come from the varying numbers of silent species inhabiting different locations and generally greater likelihood of visually spotting birds in open habitats than in forests. If we assume that the detection distance is only slightly shorter for the recorders than for observers [23], that most birds are detected by auditory cues in the field [22], and that similar species richness estimations are obtained by recorders and observers [21], then we may generalize our results also to traditional human-based point-counts where bird species richness is estimated in an unlimited radius. In studied locations, the effectiveness of the same type of recorders was compared with human point-counts. Studies reported similar bird-species-richness estimation by humanobservers and recorders in Cameroon [20] and in forests in Poland, but in open habitats in Poland, recorders detected a lower number of bird species than human-observers surveying birds at the same time [37]. During a single survey, we detected an average of $47 \%$ of the overall daily bird-species richness observed during two succeeding days at a given recording site. Correspondingly, estimates of community similarity between surveys, as quantified with Sørensen similarity index, were low (0.55-0.56). This degree of repeatability among surveys has been due to the specific methods used in our study-a 5-min survey. The accuracy and precision of single surveys have been shown to depend not only on their duration, time of day, and stage in the season, but also on the probabilities of detection of single species that make up a bird community $[11,37,38]$. Survey durations and stages of the breeding season from the perspective of a single recording site were constant in our study. Thus, variation in bird-species-richness estimation was mainly related to daily changing probabilities of detecting species that compose the bird community at a recording site. It means that, in all analyzed regions and habitat types, as in other studies (e.g., see References [39,40]), some species were easy to detect, while others were not, and the sum of probabilities of detection gave an estimation of species richness, which, in our study, did not differ between habitats. In our study, tropical and temperate locations varied in their size and the distance between neighboring recording sites. Therefore, we analyzed bird-species richness only at the recording site and did not compare species' richness between whole locations. Additionally, the effectiveness of a single survey in our study was compared to the total number of bird species detected during six surveys conducted in two succeeding days in the morning hours.

Our results also highlight a more general problem, i.e., a single point-count survey has clear limitations for assessing the spatial distribution of particular species, such as in studies of site occupancy rates or habitat preferences [41,42]. This limitation especially applies to species with low detectability. In such cases, increasing either the duration (e.g., by applying autonomous sound recorders) or number of surveys in a season may improve detectability and increase the performance of models that seek to describe relationships between birds and environmental characteristics $[40,43,44]$. We showed that a single survey conducted at sunrise recorded more species than surveys conducted one or two hours after sunrise, but it was still only $54 \%$ of overall bird species detected at the recording site during six surveys conducted by two succeeding days. We are aware that, even when conducting six surveys, we were not able to detect all bird species present around recording sites, because we did not record soundscapes at night, for example. Autonomous sound recorders are well adapted for studying bird species' richness. In the simplest approach, a 
single 24-h survey should allow for the detection of all vocalizing species present within the detection range of the recorders. Manual spectrogram scanning and listening to recordings are time-consuming, but appropriate sampling across whole days (e.g., 5 min every hour) should reduce the effort with a slight decrease of accuracy and give a good bird-speciesrichness estimation independently of the geographical region and habitat type. Sound attenuates faster in forests than in open habitats [45], so the detection ranges of the same sound by recorders and human-observers are larger in open than in forest habitats [23]. We did not apply habitat-related correction for detection range in our study, so we expect that the sampling area around recording sites was larger in the open than in the forest habitat, but still constant at the recording site. Such an approach corresponds with point-counts, applying an unlimited radius of detection.

Regardless of habitat type or region, the number of species detected in our study was highest at sunrise and lower in later surveys. This result is not surprising, because bird vocal activity is highest at dawn [46-48]. However, human-observers have a finite ability to perceive different birds, and, therefore, the probability of not detecting a species increases with the number of species vocalizing at the same time [49]. In our approach, we sought to eliminate the subjective effects of perception and observer skill by analyzing recordings in the lab; we were thus able to listen to recordings many times and compare unknown vocalizations with sound samples from online libraries. If we had used human-observers, differences between different times of day would likely have been less pronouncedhuman-observers should tend to overlook species during dawn chorus, when most species are singing than during later hours [49]. As is, our results highlight a clear effect of the time of day when surveys are conducted. If this factor is not considered in the design and interpretation of surveys, spurious changes in bird biodiversity would likely appear that do not reflect any biological or ecological process but are merely an effect of the time when surveys were conducted.

\section{Conclusions}

Our study showed that recorder-based point-counts provided similar estimates of bird biodiversity in various habitat types and geographical regions. At the same time, a low proportion of detected species during a single survey limits the usefulness of the method in studying bird-environment relationships (e.g., habitat preferences), while a decreasing number of detected species across the day may result in the misinterpretation of the status of bird populations, when early and late surveys are compared without controlling this factor. Using acoustic recorders, we missed some silent species, which could be detected by human-observers. We also focused on a very short period in the breeding season and only surveyed birds active during the day. To fully estimate bird biodiversity, repeated surveys at recording sites should be conducted across the whole year, including day and night controls. Our study was conducted only in two locations. To support our results further studies applying the same bird survey method in tropical and temperate regions are needed.

Supplementary Materials: The following are available online at https://www.mdpi.com/article/ 10.3390/birds2040026/s1. Table S1: List of bird species detected in each location. Table S2: Dataset containing ID of recording sites, geographical coordinates of recording sites, location, habitat type, date of survey, time of survey and the number of detected bird species.

Author Contributions: Conceptualization, M.B., K.K. and T.S.O.; methodology, M.B.; software, M.B. and K.K.; validation, M.B.; formal analysis, M.B. and K.K.; investigation, M.B., K.K. and T.S.O.; data curation, M.B., K.K. and T.S.O.; writing-original draft preparation, M.B.; writing-review and editing, K.K. and T.S.O.; visualization, M.B.; funding acquisition, M.B. and T.S.O. All authors have read and agreed to the published version of the manuscript.

Funding: This research was funded by the Ministry of Science and Higher Education, grant number IP2014 005073; and the National Science Center, Poland, grant number 2015/17/B/NZ8/02347 and grant number 2019/35/D/NZ8/04416. 
Institutional Review Board Statement: The study was classified as a non-animal experiment, and thus it did not require approval from a relevant body.

Data Availability Statement: The data presented in this study are available in supplementary material.

Acknowledgments: We thank Ernest Amohlon Vunan for enabling work on land belonging to the Kedjom-Keku People and for his help in organizing the field work in Cameroon. We are grateful to Anna Skierczyńska and Marcin Antczak for their help in the field, Lindsay Riggings and Agata Staniewicz for improving our writing, and two anonymous reviewers for helpful comments and suggestions.

Conflicts of Interest: The authors declare no conflict of interest.

\section{References}

1. Bibby, C.J.; Hill, D.A.; Burgess, N.D.; Mustoe, S. Bird Census Techniques, 2nd ed.; Academic Press: London, UK, 2000.

2. Matsuoka, S.M.; Mahon, C.L.; Handel, C.M.; Sólymos, P.; Bayne, E.M.; Fontaine, P.C.; Ralph, C.J. Reviving common standards in point-count surveys for broad inference across studies. Condor 2014, 116, 599-608. [CrossRef]

3. Crisol-Martínez, E.; Moreno-Moyano, L.T.; Horgan, F.G. Bioacoustics Reveal Species-Rich Avian Communities Exposed to Organophosphate Insecticides in Macadamia Orchards. Birds 2020, 1, 35-52. [CrossRef]

4. Ralph, C.J.; Sauer, J.R.; Droege, S. Monitoring Bird Populations by Point Counts; General Technical Report PSW-GTR-149, Pacific Southwest Research Station; U.S. Department of Agriculture, Forest Service: Albany, CA, USA, 1997.

5. Gregory, R.D.; Gibbson, D.W.; Donald, P. Bird census and survey techniques. In Bird Ecology and Conservation: A Handbook of Techniques; Sutherland, W.J., Newton, I., Green, R.E., Eds.; Oxford University Press: New York, NY, USA, 2004 ; pp. 17-56.

6. Tozer, D.C.; Abraham, K.F.; Nol, E. Improving the accuracy of counts of wetland breeding birds at the point scale. Wetlands 2006, 26, 518-527. [CrossRef]

7. Gale, G.; Round, P.D.; Pierce, A.J.; Nimnuan, S.; Pattanavibool, A.; Brockelman, W.Y. A field test of distance sampling methods for a tropical forest bird community. Auk 2009, 126, 439-448. [CrossRef]

8. Fuller, R.J.; Langslow, D.R. Estimating numbers of birds by point counts: How long should counts last? Bird Study 1984, 31, 195-202. [CrossRef]

9. Budka, M.; Jobda, M.; Szałański, P.; Piórkowski, H. Effect of agri-environment measure for the Aquatic Warbler on bird biodiversity in the extensively managed landscape of Biebrza Marshes (Poland). Biol. Conserv. 2019, 239, 108279. [CrossRef]

10. Burner, R.C.; Styring, A.R.; Rahman, M.A.; Sheldon, F.H. Occupancy patterns and upper range limits of lowland Bornean birds along an elevational gradient. J. Biogeogr. 2019, 46, 2583-2597. [CrossRef]

11. Drapeau, P.; Leduc, A.; McNeil, R. Refining the use of point counts at the scale of individual points in studies of bird-habitat relationship. J. Avian Biol. 1999, 30, 367-382. [CrossRef]

12. Forcey, G.M.; Anderson, J.T.; Ammer, F.K.; Whitmore, R.C. Comparison of two double-observer point-count approaches for estimating breeding bird abundance. J. Wildl. Manag. 2006, 70, 1674-1681. [CrossRef]

13. Howell, C.A.; Porneluzi, P.A.; Clawson, R.L.; Faaborg, J. Breeding density affects point-count accuracy in Missouri forest birds. J. Field Ornithol. 2004, 75, 123-133. [CrossRef]

14. Efford, M.G.; Dawson, D.K. Effect of distance-related heterogeneity on population size estimates from point counts. Auk 2009, 126, 100-111. [CrossRef]

15. Rigby, E.A.; Johnson, D.H. Factors affecting detection probability, effective area surveyed, and species misidentification in grassland bird point counts. Condor 2019, 12, 1-10. [CrossRef]

16. Celis-Murillo, A.; Deppe, J.L.; Allen, M.F. Using soundscape recordings to estimate bird species abundance, richness, and composition. J. Field Ornithol. 2009, 80, 64-78. [CrossRef]

17. Darras, K.; Batáry, P.; Furnas, B.J.; Grass, I.; Mulyani, Y.A.; Tscharntke, T. Autonomous sound recording outperforms human observation for sampling birds: A systematic map and user guide. Ecol. Appl. 2019, 29, e01954. [CrossRef] [PubMed]

18. Hutto, R.L.; Stutzman, R.J. Humans versus autonomous recording units: A comparison of point-count results. J. Field Ornithol. 2009, 80, 387-398. [CrossRef]

19. Wheeldon, A.; Mossman, H.L.; Sullivan, M.J.P.; Mathenge, J.; de Kort, S.R. Comparison of acoustic and traditional point count methods to assess bird diversity and composition in the Aberdare National Park, Kenya. African J. Ecol. 2019, 57, 168-176. [CrossRef]

20. Sedláček, O.; Vokurkova, J.; Ferenc, M.; Djomo, E.N.; Albrecht, T.; Horak, D. A comparison of point counts with a new acoustic sampling method: A case of a bird community from the montane forests of Mount Cameroon. Ostrich 2015, 86, 1-8. [CrossRef]

21. Darras, K.; Batáry, P.; Furnas, B.; Celis-Murillo, A.; van Wilgenburg, S.L.; Mulyani, Y.A.; Tscharntkeet, T. Comparing the sampling performance of sound recorders versus point counts in bird surveys: A meta-analysis. J. Appl. Ecol. 2018, 55, 2575-2586. [CrossRef]

22. Brewster, J.P.; Simons, T.R. Testing the importance of auditory detections in avian point counts. J. Field Ornithol. 2008, 80, 178-182 [CrossRef] 
23. Yip, D.; Leston, L.; Bayne, E.; Sólymos, P.; Grover, A. Experimentally derived detection distances from audio recordings and human observers enable integrated analysis of point count data. Avian Conserv. Ecol. 2017, 12, 11. [CrossRef]

24. Sauer, J.R.; Peterjohn, B.C.; Link, W.A. Observer differences in the North American Breeding Bird Survey. Auk 1994, 111, 50-62. [CrossRef]

25. Farmer, R.G.; Leonard, M.L.; Flemming, J.E.M.; Anderson, S.C. Observer aging and long-term avian survey data quality. Ecol. Evol. 2014, 4, 2563-2576. [CrossRef] [PubMed]

26. IMGW. Climate of Poland; Institute of Meteorology and Water Management National Research Institute: Warsaw, Poland, 2020.

27. Budka, M. Upper Nurzec River Valley. In Important Bird Areas of International Importance in Poland; Wilk, T., Jujka, M., Krogulec, J., Chylarecki, P., Eds.; Polish Society for the Protection of Birds: Marki, Poland, 2010.

28. Wesołowski, T.; Czeszczewik, D.; Hebda, G.; Maziarz, M.; Mitrus, C.; Rowiński, P. 40 years of breeding bird community dynamics in a primeval temperate forest (Białowieża National Park, Poland). Acta Ornithol. 2015, 50, 95-120. [CrossRef]

29. BirdLife International. Endemic Bird Areas factsheet: Cameroon mountains. Available online: http://www.birdlife.org (accessed on 24 October 2020).

30. Tye, H. The climate of the highlands of western Cameroon. In Conservation of Cameroon Montane Forests; Stuart, S.N., Ed.; International Council for Bird Preservation: Cambridge, UK, 1986; pp. 18-19.

31. Innocent, N.M.; Bitondo, D.; Azibo, B.R. Climate variability and change in the Bamenda highlands of north western Cameroon: Perceptions, impacts and coping mechanisms. Br. J. Appl. Sci. Technol. 2016, 12, 1-18. [CrossRef]

32. Tye, H. Reversal of breeding season by lowland birds at higher altitudes in western Cameroon. Ibis 1992, 134, 154-163. [CrossRef]

33. Sedláček, O.; Reif, J.; Hořák, D.; Riegert, J.; Pešata, M.; Klvana, P. The birds of a montane forest mosaic in Big Babanki area, Bamenda Highlands, Cameroon. Malimbus 2007, 29, 89-100.

34. Bonthoux, S.; Balent, G. Point count duration: Five minutes are usually sufficient to model the distribution of bird species and to study the structure of communities for a French landscape. J. Ornithol. 2012, 153, 491-504. [CrossRef]

35. Hardin, J.W.; Hilbe, J.M. Generalized Estimating Equations, 2nd ed.; Chapman and Hall/CRC: Boca Raton, FL, USA, 2013.

36. Sørensen, T. A method of establishing groups of equal amplitude in plant sociology based on similarity of species and its application to analyses of the vegetation on Danish commons. K. Dan. Vidensk. Selsk. 1948, 5, 1-34.

37. Kułaga, K.; Budka, M. Bird species detection by an observer and an autonomous sound recorder in two different environments: Forest and farmland. PLoS ONE 2019, 14, e0211970. [CrossRef]

38. Harms, T.M.; Dinsmore, S.J. Optimizing surveys for marsh songbirds: Does timing matter? J. Field Ornithol. 2018, 89, 276-286. [CrossRef]

39. Kéry, M.; Schmidt, B.R. Imperfect detection and its consequences for monitoring for conservation. Comm. Ecol. 2008, 9, 207-216. [CrossRef]

40. Sliwinski, M.; Powell, L.; Koper, N.; Giovanni, M.; Schacht, W. Research design considerations to ensure detection of all species in an avian community. Methods Ecol. Evol. 2016, 7, 456-462. [CrossRef]

41. MacKenzie, D.; Nichols, J.; Lachman, G.; Droege, G.S.; Royle, J.; Langtimm, C. Estimating site occupancy rates when detection probabilities are less than one. Ecology 2002, 83, 2248-2255. [CrossRef]

42. Gu, W.; Swihart, R.K. Absent or undetected? Effects of non-detection of species occurrence on wildlife-habitat models. Biol. Conserv. 2003, 116, 195-203. [CrossRef]

43. Dettmers, R.; Buehler, D.; Bartlett, J.; Klaus, N. Influence of point count length and repeated visits on habitat model performance. J Wild Manag. 1999, 63, 815-823. [CrossRef]

44. Budka, M.; Czyż, M.; Skierczyńska, A.; Skierczyński, M.; Osiejuk, T.S. Duration of survey changes interpretation of habitat preferences: An example of an endemic tropical songbird, the Bangwa Forest Warbler. Ostrich 2020, 91, 195-203. [CrossRef]

45. Yip, D.; Bayne, E.; Sólymos, P.; Campbell, J.; Proppe, D. Sound attenuation in forest and roadside environments: Implications for avian point-count surveys. Condor 2017, 119, 73-84. [CrossRef]

46. Catchpole, C.K. The functions of advertising song in the Sedge Warbler (Acrocephalus schoenobaenus) and the Reed Warbler (A. scirpaceus). Behaviour 1973, 46, 300-319. [CrossRef]

47. Gil, D.; Llusia, D. The bird dawn chorus revisited. In Coding Strategies in Vertebrate Acoustic Communication; Aubin, T., Mathevon, N., Eds.; Springer Nature: London, UK, 2020; pp. 45-92.

48. Bateman, H.L.; Riddle, S.B.; Cubley, E.S. Using Bioacoustics to Examine Vocal Phenology of Neotropical Migratory Birds on a Wild and Scenic River in Arizona. Birds 2021, 2, 261-274. [CrossRef]

49. Haselmayer, J.; Quinn, J.S. A comparison of point counts and sound recording as bird survey methods in Amazonian Southeast Peru. Condor 2000, 102, 887-893. [CrossRef] 